\title{
Why are the mentally handicapped still admitted to hospital?
}

\author{
Leila B. Cooke, Consultant Psychiatrist, Stoke Park Hospital, Stapleton, \\ Bristol BS16 1QU
}

The Stoke Park Hospital Group in Bristol has been providing a service to mentally handicapped people and their families since 1909. The nature and extent of the service has changed significantly between then and now, largely due to changes in Government policy, first laid out in the 1971 white paper Better Services for the Mentally Handicapped. The changing nature of the service was highlighted in Carter's paper in 1984, in which he examined all admissions to the Group over ten years. He found an increasing use of the hospitals for short-term care, particularly for those patients with a superimposed psychiatric disorder, and a continuing, albeit reducing, demand for long-term care for some patients. He concluded that the hospital would continue to have an important role to play in the evolving pattern of care.

There have been surprisingly few evaluative studies of the use of mental handicap hospitals since. A study in Denmark noted a rapid increase in the numbers of mentally retarded people being admitted to psychiatric hospitals following the dismantling of the specialist mental handicap services. Rao (1987) found a dramatic increase in short-term admissions to Ely Hospital, Cardiff between 1970 and 1983, with a preponderance of behavioural, medical and psychiatric problems. Dickinson \& Singh (1991) highlighted the emergence of a new long-stay population in their examination of admissions to Leavesden Hospital over four years.

The South West Regional Health Authority is now implementing a policy of rapid closure of all mental handicap hospitals, without planning alternative specialist services. It was therefore felt timely to repeat Carter's study and examine the use of the hospital service since the publication of his paper.

\section{The study}

All admissions to the Stoke Park Group of Hospitals for the period 1984-1991 were examined. From January 1984-March 1987 all admissions had been recorded manually. From April 1987, the system has been computerised and the computer used to obtain total numbers of short and long-term admissions and total numbers of people using the service.

For financial reasons, all admissions which extend for more than $\mathbf{6 0}$ days are categorised as long-term; therefore it was convenient to define admissions as short or long-term on this basis for the purpose of the study. Short-term admissions were divided into those for planned respite care, those for psychiatric or medical assessment and treatment, and emergency admissions for crisis intervention. Case-notes were examined in order to extract psychiatric, medical and social information.

\section{Findings}

The Stoke Park Hospital Group currently has 518 beds on three sites and serves a catchment population of 224,000 . Two hundred and thirty-six people have used the in-patient service over the last eight years, with an average of 97 people using it per year, in addition to the existing long-stay population. One of the principles of service provision is that it covers the whole life span, and the age range of service users during the period of the study was two to 82 years. Forty-eight children ( $<16$ years) have used the service, $20 \%$ of the overall number.

\section{Short-term admissions}

From 1984-1991 there was a total of 4,447 admissions for short-term care, an average of 556 per year. There has been a steady increase in the number of short-term admissions, from 388 in 1984 to 819 in 1991, more marked in the last three years. This may be associated with the opening of a short-term care unit based in two ordinary houses on the periphery of the hospital. Of short-term admissions, $91 \%$ were for planned respite care, and this proportion remained constant. Admissions for psychiatric or medical assessment and/or treatment accounted for $5 \%$ of the total, and emergency admissions for $4 \%$. Again, these proportions remained constant over time. Respite care is usually only provided for those families already receiving other services from members of the community mental handicap teams, i.e. only those patients with specialist health needs are admitted.

\section{Long-term admissions}

There were 84 long-term admissions from 19841991, an average of ten per year. The numbers are 
TABLE I.

Analysis of factors associated with long-term admissions

Psychiatric disorder

Deterioration of functional psychosis

Behavioural disorder

Dementia

Others (1 Asperger's syndrome,

1 Acute confusional state)

Family factors

Death of parent

Parental illness

Physical health

Deterioration following discharge

Post-operative care

Deterioration following death of parent

Severe epilepsy

Geographical factors

Transfers from other hospitals

Transfers from special schools
2 Personality disorder,

Increasing parental age

increasing, from 16 in the first two years of the study to 32 in the last two years. Thirty-six patients $(43 \%)$ had had short-term admissions prior to becoming long term in-patients. The average age on admission was 40 years (range $12-75$ ) and $63 \%$ were male. The average IQ of the patients was 45 (range 13-88). IQ scores were available on 73 patients.

The main factors contributing to the long-term admissions were analysed. By far the largest contributory factor was psychiatric disorder, which accounted for $58 \%$ of the total admissions. Eight patients $(10 \%)$ were detained under the Mental Health Act, 1983. The second largest was family factors at $16 \%$, and third was problems with physical health, which accounted for $11 \%$. Other factors mentioned were geographical reasons, the patients' own wishes, referral by Courts and multiple handicap. Table I gives a more detailed analysis of the factors associated with long-term admissions.

Analysis of the place of residence prior to admission showed that the largest number, $39(46 \%)$, were admitted from the family home. Of the total admissions, $34(40 \%)$ were readmissions. The largest number of those came from the local health authority trust homes, followed by the private and voluntary sector. The reasons for readmissions fell into three major categories: psychiatric disorder 21 (62\%); medical problems $7(21 \%)$; and patient wishing to return to hospital $6(18 \%)$.

\section{Comment}

The results indicate the considerable extent to which the mental handicap hospitals in this area are still being used. Admissions to both short-term and longterm care are increasing. At the commencement of Carter's study in 1974, there were 174 admissions for short-term care in a year. Seventeen years later, in 1991 , there were 819 from the same catchment area. This enormous increase indicates the effect that the implementation of community care has had upon patterns of service provision. From the early 1970s, people with a mental handicap were no longer automatically admitted to hospital in childhood, but were kept at home to be cared for by their families. Those children are now young adults and in some cases increasingly difficult to look after at home. Hence the continuously rising demand for more short-term care. The only respite care currently provided in the district by Avon Social Services is the Family Support Scheme, which has a limited number of places for children to have regular stays with a named family, and a small number of respite beds for adults and children within hostels, which have to be booked well in advance. Neither facility can cope with people who are behaviourally difficult or who have complex psychiatric or medical needs. The advantage of NHS respite is that the staff are RNMH trained, and there is regular psychiatric, medical and other multidisciplinary input. The rapid increase in use of the service since the opening of the new short-term care unit may indicate that this is more acceptable to families than the previous option of admission to a ward within the hospital.

People with a mental handicap are now living longer and becoming susceptible to additional mental and physical diseases and disorders associated with ageing. Their parents are becoming elderly and frail and unable to cope with looking after them. The sharp increase in long-term admissions over the last three years is in part an indication of the lack of community residential provision for those families who now require it. At present there are no plans to expand local provision by Avon Social Services or the private and voluntary sector, and no joint planning is taking place on the subject.

The survey has also highlighted the changing nature of NHS services for people with a mental handicap. By far the most common factor leading to long-term admission was psychiatric disorder (58\%). In Carter's study (1984), psychiatric disorder was the 
main factor in only $15 \%$, and less significant than family $(42 \%)$ and geographical factors $(37 \%)$. Since then the emphasis of NHS services for the mentally handicapped has become more clearly focused on their psychiatric needs. Papers in recent years have demonstrated the high prevalence of psychiatric illness in people with a mental handicap. Day (1985) found that $30 \%$ of long-stay hospital patients and $20 \%$ of patients admitted from the community over the age of 40 had a psychiatric disorder. Gillberg et al (1986) found a handicapping psychiatric condition in $64 \%$ of severely retarded and $57 \%$ of mildly retarded children aged 13-17. Ballinger et al (1991) estimated from their study of 100 hospital residents that 30 psychiatric mental handicap beds were required per 100,000 population.

The current study indicates an increasing prevalence when compared with Carter's functional psychoses and behavioural problems which in some were indicative of underlying neurotic disorder. This increase may to an extent be attributable to the stress of community living. Inability to find suitable employment or day care, loss through bereavement of parents and friends, and increased susceptibility to abuse may all contribute to this.

Lack of acceptance by, and lack of integration into, the community was certainly a significant factor in patients re-admitted following discharge from long-term hospital care. That $62 \%$ of readmissions were for psychiatric disorder indicates how stressful discharge from hospital can be for someone who has lived there a long time, and emphasises the need for adequate preparation and close supervision by a psychiatrist after discharge. It may also indicate that psychiatric illness in someone with mental handicap is more likely to be chronic and refractory. In some cases a deterioration in physical health after discharge necessitated readmission. It is particularly disturbing that $40 \%$ of all admissions are readmissions, because there has been a tendency to discharge those patients with the least psychiatric and medical problems first. If this readmission rate continues or increases it has significant implications for the hospital closure programme.

This study indicates the extent of the need for specialist psychiatric services for people with a mental handicap. It is to be welcomed that the need for these services has been recognised by the Government in recent years which stressed the need for specialist assessment and treatment services, and NHS residential care and short-term care for "a small number of people with severe or profound learning disabilities, and physical, sensory or psychiatric conditions".
It is difficult at present to calculate with any accuracy the actual numbers of beds which will be required in the future. The Stoke Park Group currently has 26 beds which are reserved for short-term care for a catchment population of 224,000 , i.e. 11 per 100,000 population. The occupancy rate of these is $59 \%$. It is not possible to achieve a higher overall occupancy without having to turn people away at peak times, i.e. weekends and holidays.

Out of a total of 84 long-term admissions in eight years, 52 patients are still in hospital because we have been unable to discharge them to the community provision available. This means that we are accumulating an average of seven new long-stay patients per year. Given that the average age on admission was 40 years, and the mean lifespan of a person with a mental handicap is now 64 years, the minimum number of NHS long-stay beds required in the future will be 24 , i.e. 11 per 100,000 population. However, if the rate of increase in long-term admissions over the last three years continues, it could be considerably higher than this.

It is therefore estimated that a minimum of 22 beds ( 11 long-stay, 11 short-stay) per 100,000 population will be required in the future to provide NHS specialist services for people with a mental handicap.

\section{Acknowledgements}

I would like to thank Dr J. Jancar for his help and advice and Mrs Shirley Hodges for obtaining statistics.

\section{References}

Ballinger, B. R., Ballinger, C. B., Reid, A. H. et al (1991) The psychiatric symptoms, diagnoses and care needs of 100 mentally handicapped patients. British Journal of Psychiatry, 158, 251-254.

CARTER, G. (1984) Why are the mentally handicapped admitted to hospital? A ten-year survey. British Journal of Psychiatry, 145, 283-288.

DAY, K. A. (1985) Psychiatric disorder in the middle-aged and elderly mentally handicapped. British Journal of Psychiatry, 147, 660-667.

Dickinson, M. J. \& Singh, I. (1991) Mental handicap and the new long stay. Psychiatric Bulletin, 15, 334-335.

Gillberg, C., Persson, E., Grufman, M. et al (1986) Psychiatric disorders in mildly and severely mentally retarded urban children and adolescents: epidemiological aspects. British Journal of Psychiatry, 149, 68-74.

RAO, J. M. (1987) Trends in short term and long term care admissions to a hospital of the mentally handicapped and the influence of socio-economic, familial and clinical factors. Social Psychiatry, 22, 118-122.

A full list of references is available on request to the author. 